\title{
RADIOCARBON INVESTIGATION OF THE SUPERLATIVE AFRICAN BAOBABS FROM SAVÉ VALLEY CONSERVANCY, ZIMBABWE
}

\author{
ADRIAN PATRUTTa, ${ }^{*}$, ROXANA T. PATRUT $^{a}$, LASZLO RAKOSY ${ }^{b}$, \\ DANIEL A. LOWYc, DRAGOS MARGINEANUa, KARL F. VON REDEN ${ }^{d}$
}

\begin{abstract}
The article reports the radiocarbon investigation results of the superlative African baobabs from Savé Valley, Zimbabwe. Several wood samples collected from these baobab were analysed by AMS (accelerator mass spectrometry) radiocarbon dating. The radiocarbon dates of the oldest samples were $1529 \pm 14$ BP for Matendere Big baobab, $1179 \pm 19$ BP for Chishakwe Big tree and $1096 \pm 35 \mathrm{BP}$ for Mokore Giant baobab. The corresponding calibrated ages are $1430 \pm 15,1090 \pm 40$ and $1020 \pm 25$ calendar yr. The oldest tree from Savé Valley, which we described previously, is the Humani Bedford Old baobab. The radiocarbon date of its oldest sample, $1655 \pm 14 \mathrm{BP}$, corresponds to a calibrated age of $1580 \pm 30$ calendar yr.
\end{abstract}

Keywords: AMS radiocarbon dating, Adansonia digitata, tropical trees, dendrochronology, age determination, Zimbabwe.

\section{INTRODUCTION}

The African baobab (Adansonia digitata L.), which belongs to the Bombacoideae, a subfamily of Malvaceae, is the best known of the eight or nine Adansonia species. The African baobab has a natural distribution in the tropical arid savanna regions of mainland Africa between the latitudes $16^{\circ} \mathrm{N}$ and $26^{\circ} \mathrm{S}$. It can also be found on several African islands and outside Africa, in different areas throughout the tropics, where it has been introduced [1-5].

a Babeş-Bolyai University, Faculty of Chemistry and Chemical Engineering, 11 Arany Janos, RO-400028, Cluj-Napoca, Romania

b Babeş-Bolyai University, Faculty of Biology and Geology, 44 Republicii, RO-400015, ClujNapoca, Romania

c VALOR HUNGARIAE, Dept. of Science and Innovation, 4 Nagysándor József, 1054 Budapest, Hungary

d NOSAMS Facility, Dept. of Geology \& Geophysics, Woods Hole Oceanographic Institution, Woods Hole, MA 02543, U.S.A.

*Corresponding author: apatrut@gmail.com 
In 2005 , we started an extended research project to elucidate several controversial aspects related to the architecture, growth and age of the African baobab and of other large and/or old baobab species. This research is based on our new approach, which is not limited to fallen specimens, but allows to investigate and date live individuals, as well. Our approach consists of AMS (accelerator mass spectrometry) radiocarbon dating of tiny wood samples collected especially from inner cavities, deep incisions/entrances in the stems, fractured stems and from the outer part/exterior of large baobabs [6-12].

The majority of baobabs start growing as single-stemmed trees. Nevertheless, over time, single-stemmed individuals become multi-stemmed, owing to the baobabs' ability to produce periodically new stems, such as other tree species produce branches. By this special capacity, baobabs develop over time architectures of increasing complexity. Therefore, we focused on the investigation of superlative individuals, i.e., very large and potentially old baobabs. One should emphasize that neither the identification of such very complex architectures nor the accurate age determination of old baobabs are possible via traditional dendrochronological methods based on tree ring investigation [13]. The oldest dated African baobab specimens were found to have ages greater than $2000 \mathrm{yr}$ [13-15]. By these values, the African baobab becomes the longest living angiosperm.

The Savé Valley Conservancy is a large wildlife area $\left(3442 \mathrm{~km}^{2}\right)$, located in the semi-arid South East Lowveld of Zimbabwe, at an altitude of 480-620 m. It consists of multiple properties owned by private ranchers, local councils, government and a local community [16]. Savé Valley hosts thousands African baobabs, out of which four are superlative specimens. All these very large and old trees are located to the north of Turgwe river, more precisely in the Matendere, Chishakwe, Mokore and Humani ranches.

In a previous article, we presented the AMS radiocarbon dating results of the Humani Bedford Old baobab, which is not only the oldest tree of Zimbabwe, but also the oldest living African baoab [17].

Here we also disclose the results of the radiocarbon investigation of the other three superlative baobabs from the Savé Valley Conservancy.

\section{RESULTS AND DISCUSSION}

The superlative baobabs and their areas. The four superlative baobabs are located on four ranches, which belong to the Savé Valley Conservancy, Chiredzi district, Zimbabwe. The mean annual rainfall in these areas is between 360-460 mm. 
The northernmost superlative baobab is the Matendere Big baobab, which was discovered in 1994 by Léon Duplessis on the Matendere Ranch. Its GPS coordinates are $20^{\circ} 00.325^{\prime} \mathrm{S}, 032^{\circ} 03.808^{\prime} \mathrm{E}$ and the altitude is $702 \mathrm{~m}$. It has a height $\mathrm{h}=22.5 \mathrm{~m}$, the circumference at breast height (cbh; at $1.30 \mathrm{~m}$ above ground level) is cbh $=26.30 \mathrm{~m}$ and the overall wood volume (trunk and branches, including the cavity) is around $300 \mathrm{~m}^{3}$.

The Matendere Big baobab is composed of 7 large units, which correspond to stems. It has a closed ring-shaped structure defined by 5 stems that incorporate a false cavity, with a very tall opening at a height of over $6 \mathrm{~m}$. Its canopy has the horizontal dimensions of $38.3 \times 39.4 \mathrm{~m}$.

A second representative baobab of Savé Valley, i.e., the Chishakwe Big tree, can be found on the Chishakwe Ranch. The GPS coordinates are $20^{\circ} 06.656^{\prime} \mathrm{S}, 032^{\circ} 04.991^{\prime} \mathrm{E}$ and the altitude is $588 \mathrm{~m}$. It has the following dimensions: $\mathrm{h}=26.1 \mathrm{~m}$, cbh $=26.56 \mathrm{~m}, \mathrm{~V}=$ ca. $375 \mathrm{~m}^{3}$ (Figure 1). The Chishakwe Big tree consists of 7 fused stems. It has a closed ring-shaped structure, with a ring composed of 5 or 6 stems that completely close a false cavity inside. The cavity has only a tall opening at a height of 7-8 m, which is inaccessible. The large canopy has the horizontal dimensions of $38.5 \times 36.1 \mathrm{~m}$.

The Humani Bedford Old baobab, that we previously dated [17], is located on the Bedford Block of the Humani Ranch. It was discovered only in 2011 by Roger and Anne Whittall. The GPS coordinates are $20^{\circ} 24.474$ ' S, $032^{\circ} 14.135^{\prime} \mathrm{E}$ and the altitude is $432 \mathrm{~m}$. Its dimensions are: $\mathrm{h}=18.2 \mathrm{~m}$, $\mathrm{cbh}=23.65 \mathrm{~m}, \mathrm{~V}=240 \mathrm{~m}^{3}$. The big trunk has a closed ring-shaped structure which consists now of three fused stems (one stem is missing) that partially close a false cavity with the walls covered by bark. The Humani baobab has huge branches, with diametres up to $2.2 \mathrm{~m}$, which form a canopy with the horizontal dimensions of $27.2 \times 24.7 \mathrm{~m}$.

The best-known baobab of Savé Valley, the Mokore Giant baobab, is located on the Mokore Ranch. It has the following GPS coordinates: $20^{\circ} 23.950^{\prime}$ $\mathrm{S}, 036^{\circ} 06.836^{\prime} \mathrm{E}$ and the altitude is $462 \mathrm{~m}$. Its dimensions are: $\mathrm{h}=23.2 \mathrm{~m}$, $\mathrm{cbh}=28.11 \mathrm{~m}$ and $\mathrm{V}=\mathrm{ca}$. $320 \mathrm{~m}^{3}$ (Figure 2). The Mokore Giant baobab possesses 7 stems of different sizes and ages and a large false stem, which acts as a structural support/anchor. The false stem is mainly empty and fissured; this might have dramatic consequences on the survival of this specimen in the near future. The Mokore baobab has a closed ring-shaped structure, with a ring of 4 stems that close a false cavity. The cavity has an opening only in the upper part, at a height of over $5 \mathrm{~m}$. The horizontal dimensions of the very large canopy are $42.3 \times 35.1 \mathrm{~m}$.

The Matendere Big baobab and the Humani Bedford Old baobab are basically unknown in the literature, as well as outside Savé Valley; they are not included in the registers of the Tree Society of Zimbabwe. 
Wood samples. Several samples were collected from the walls of the inner cavity (Humani Bedford), as well as from deep incisions in the exterior/ outer part (Matendere, Chishakwe, Mokore) of the four baobabs. The heights of the sampling points were between 1.36 and $2.05 \mathrm{~m}$. A number of tiny pieces/ segments, each $0.1 \mathrm{~cm}$ long, were extracted from determined positions of each sample.

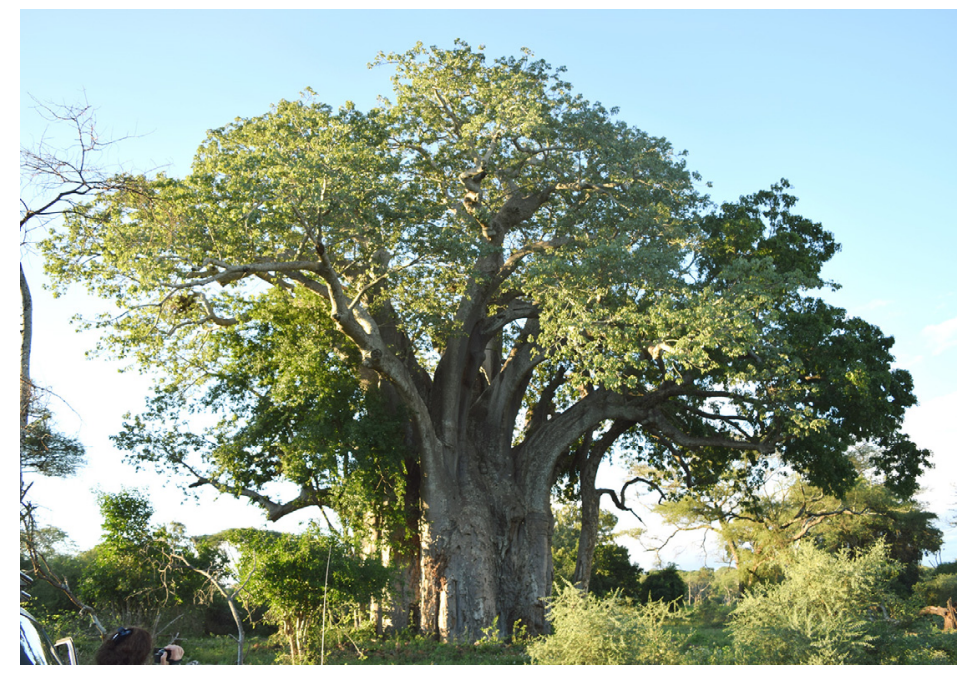

Figure 1. The Chishakwe Big tree is the tallest and largest African baobab of Zimbabwe (26.1 m, $\left.375 \mathrm{~m}^{3}\right)$.

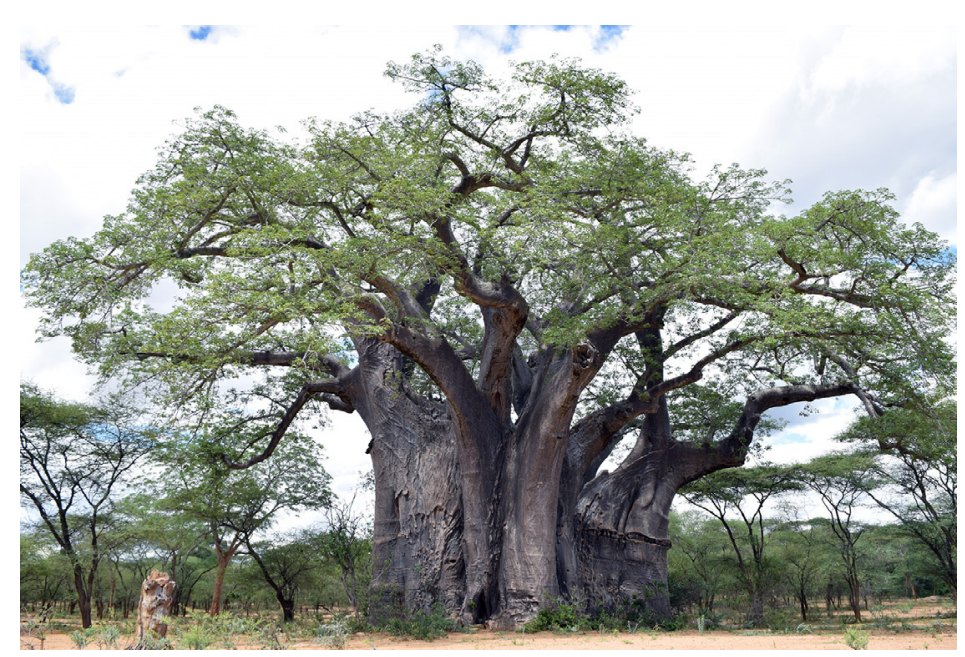

Figure 2. The Mokore Giant baobab has the biggest circumference $(28.11 \mathrm{~m})$ of all trees of Zimbabwe. 
AMS results and calibrated ages. Radiocarbon dates of the two oldest samples/segments extracted from each baobab are listed in Table 1. Radiocarbon dates and errors were rounded to the nearest year. The radiocarbon dates are expressed in ${ }^{14} \mathrm{C}$ yr BP (radiocarbon years before present, i.e., before the reference year $A D$ 1950).

Calibrated (cal) ages, expressed in calendar years, are also presented in Table 1. The 1- $\sigma$ probability distribution was selected to derive calibrated age ranges. For four samples, the $1-\sigma$ distribution is consistent with only one range of calendar years, while for the other four samples the 1- $\sigma$ distribution corresponds to two or three ranges of calendar years. For these segments, the confidence interval of one range is considerably greater than that of the other(s); therefore, it was selected as the cal AD range of the segment for the purpose of this discussion. For obtaining single calendar age values of sample segments, we derived a mean calendar age of each segment from the selected range (marked in bold). Calendar ages of samples represent the difference between AD 2019 and the mean value of the selected range, with the corresponding error. Calendar ages and errors were rounded to the nearest $5 \mathrm{yr}$.

Table 1. AMS Radiocarbon dating results and calibrated calendar ages of samples collected from superlative baobabs from Savé Valley Conservancy

\begin{tabular}{|c|c|c|c|c|}
\hline Tree & $\begin{array}{l}\text { Sample/ } \\
\text { segment } \\
\text { code }\end{array}$ & $\begin{array}{c}\text { Radiocarbon date } \\
\text { of oldest sample(s) } \\
\text { [error] } \\
\left({ }^{14} \mathrm{C} \text { yr BP }\right)\end{array}$ & $\begin{array}{c}\text { Cal AD range } \\
1-\sigma \\
\text { [confidence interval] }\end{array}$ & $\begin{array}{l}\text { Sample age } \\
\text { [error] } \\
\text { (cal yr) }\end{array}$ \\
\hline \multirow[t]{2}{*}{$\begin{array}{l}\text { Matendere } \\
\text { Big baobab }\end{array}$} & MAT-1 & $1529[ \pm 14]$ & $\begin{array}{c}552-556[3.3 \%] \\
572-604[56.3 \%] \\
618-627[8.6 \%]\end{array}$ & $1430[ \pm 15]$ \\
\hline & MAT-2 & $1305[ \pm 19]$ & $\begin{array}{c}\text { 684-738 [59.3\%] } \\
762-771[8.9 \%]\end{array}$ & $1310[ \pm 25]$ \\
\hline \multirow{2}{*}{$\begin{array}{l}\text { Chishakwe } \\
\text { Big tree }\end{array}$} & $\mathrm{CH}-1$ & $1179[ \pm 34]$ & $888-970$ [68.2\%] & $1090[ \pm 40]$ \\
\hline & $\mathrm{CH}-2$ & $1065[ \pm 24]$ & $994-1026[68.2 \%]$ & $1010[ \pm 15]$ \\
\hline $\begin{array}{l}\text { Humani } \\
\text { Bedford }\end{array}$ & HB-1 & $1655[ \pm 14]$ & $410-469[68.2 \%]$ & $1580[ \pm 30]$ \\
\hline Old baobab & HB-2 & $1375[ \pm 20]$ & $\begin{array}{l}658-682[50.2 \%] \\
746-757[18.0 \%]\end{array}$ & $1350[ \pm 10]$ \\
\hline \multirow{2}{*}{$\begin{array}{c}\text { Mokore } \\
\text { Giant baobab }\end{array}$} & MOK-1 & $1096[ \pm 35]$ & $972-1026[68.2 \%]$ & $1020[ \pm 25]$ \\
\hline & MOK-2 & $990[ \pm 18]$ & $\begin{array}{c}1042-1050[7.7 \%] \\
1080-1145[60.5 \%]\end{array}$ & $910[ \pm 30]$ \\
\hline
\end{tabular}


Dating results of oldest samples (segments). The two oldest samples originating from the Matendere Big baobab, labelled MAT-1 and MAT-2, were found to have radiocarbon dates of $1529 \pm 14$ and $1305 \pm 19$ BP (before present, i.e., before the reference year AD 1950). These values correspond to old calibrated ages, namely $1430 \pm 15$ and $1310 \pm 25$ calendar yr.

The two oldest samples extracted from the Chishakwe Big tree, i.e., $\mathrm{CH}-1$ and $\mathrm{CH}-2$, had radiocarbon dates of $1179 \pm 19$ and $1065 \pm 24$ BP. These dates correspond to calibrated ages of $1090 \pm 40$ and $1010 \pm 15$ calendar yr.

For the Mokore Giant baobab, the oldest samples MOK-1 and MOK2 have radiocarbon dates of $1096 \pm 35$ and $990 \pm 18 \mathrm{BP}$. These values correspond to calibrated ages of $1020 \pm 25$ and $910 \pm 30$ calendar yr.

We previously disclosed the radiocarbon dating results of samples collected from the Humani Bedford Old baobab. The two oldest samples HB-1 and HB-2 were found to have radiocarbon dates of $1655 \pm 14$ and $1375 \pm 20 \mathrm{BP}$. These dates correspond to calibrated ages of $1580 \pm 30$ and $1350 \pm 10$ calendar yr [17].

Architecture of the superlative baobabs. All four superlative baobabs of the Savé Valley Conservancy possess a closed ring-shaped structure with a false cavity inside. This special type of architecture enables baobabs to reach large sizes and old ages. We remind that false cavities, which have the walls covered by bark, are in fact natural empty spaces between several fused stems disposed in a closed ring-shaped structure. Over time, false cavities close progressively. Several false cavities have closed completely over time, retaining only one or several small openings. The thickness of the cavity walls, i.e., of the fused stems that define the false cavity, is of only 1-2 m. For wood samples collected from the false cavity walls toward the exterior, as well as in the case of samples collected from the exterior toward the false cavity, the age sequence shows a continuous increase from the sampling point up to a certain distance into the wood, after which it decreases in the opposite direction. The oldest part of the fused stems is located between the false cavity walls and the exterior of each stem, always closer to the cavity, in an area that would be accessible to the increment borer and allows to collect very old samples $[12,13,15,18]$.

Three superlative baobabs (Matendere, Chishakwe, Mokore) have their false cavity completely closed, with the exception of a high opening positioned at 5-8 $\mathrm{m}$ above the ground. Their false cavity can be observed only by climbing the trunk of the baobab or with the help of a drone. The fourth superlative baobab (Humani Bedford) also had its false cavity quasicompletely closed several centuries ago. The cavity has now a large opening after the collapse of a fourth stem of the ring. 
Ages of the superlative baobabs. The oldest dated samples/segments originate from the false cavity only for the Humani Bedford Old baobab. In this direction, the distance from the false cavity to the exterior/outer part, i.e., the width of the cavity walls, was found to be $1.20 \mathrm{~m}$. We also evinced the presence of the growth stop phenomenon. Radiocarbon dating results demonstrated that the oldest dated stem stopped growing toward the false cavity $600 \mathrm{yr}$ ago, while it has continued its growth toward the exterior for almost $250 \mathrm{yr}$.

By considering the sample/segment positions and ages, the growth stop and the width of the cavity walls, we estimated that the investigated stem of the Humani-Bedford baobab has an age of $1800 \pm 100 \mathrm{yr}$. By this value, it becomes the oldest living African baobab [17].

For the other three superlative baobabs, the oldest samples/segments were collected from the exterior toward the false cavity. In these cases, we cannot determine the width of the cavity walls and we have no concrete evidence about the growth stop. We can only state that the age of the oldest part of each tree is certainly older than the oldest dated sample/segment. In a conservative estimate, we assume that their ages would be: $1500 \pm 100 \mathrm{yr}$ for the Matendere Big baobab, $1200 \pm 100 \mathrm{yr}$ for the Chishakwe Big tree and also for the Mokore Giant baobab.

\section{CONCLUSIONS}

Our research discloses the AMS radiocarbon dating results of the four superlative African baobabs from the Savé Valley Conservancy, Zimbabwe. These baobabs are: the Matendere Big baobab, the Chishakwe Big tree, the Humani Bedford Old baobab and the Mokore Giant baobab. The main aim of the research was to establish the architectures and the ages of these trees.

All four baobabs exhibit a closed ring-shaped structure with a false cavity inside. This architecture consists of several fused stems around a natural empty space, which we named false cavity.

Several wood samples collected from the baobabs were radiocarbon dated. The radiocarbon dates of the oldest samples were found to be $1529 \pm 14$ BP for the Matendere Big baobab, $1179 \pm 19$ BP for the Chishakwe Big tree and $1096 \pm 35 \mathrm{BP}$ for the Mokore Giant baobab. These values correspond to calibrated ages of $1430 \pm 15,1090 \pm 40$ and $1020 \pm 25$ calendar yr.

However, the oldest tree from Savé Valley, which we have previously described, is the Humani Bedford Old baobab. The radiocarbon date of its oldest sample, i.e., $1655 \pm 14$ BP, corresponds to a calibrated age of $1580 \pm 30$ calendar yr. 
ADRIAN PATRUT, ROXANA T. PATRUT, LASZLO RAKOSY, DANIEL A. LOWY, DRAGOS MARGINEANU, KARL F. VON REDEN

\section{EXPERIMENTAL SECTION}

Sample collection. The wood samples were collected with a Haglöf $\mathrm{CH} 800$ increment borer ( $80 \mathrm{~cm}$ long, $0.54 \mathrm{~cm}$ inner diametre). A number of tiny pieces/segments of the length of $0.1 \mathrm{~cm}$ were extracted from predetermined positions along the wood samples. The segments were processed and investigated by AMS radiocarbon dating.

Sample preparation. The standard acid-base-acid pretreatment method was used for removing soluble and mobile organic components [19]. The pretreated samples were combusted to $\mathrm{CO}_{2}$ by using the closed tube combustion method [20]. Then, $\mathrm{CO}_{2}$ was reduced to graphite on iron catalyst, under hydrogen atmosphere [21]. Finally, the resulting graphite samples were analysed by AMS.

AMS measurements. AMS radiocarbon measurements were performed at the NOSAMS Facility of the Woods Hole Oceanographic Institution (Woods Hole, MA, U.S.A.) by using the Pelletron ${ }^{\circledR}$ Tandem 500 kV AMS system. The obtained fraction modern values, corrected for isotope fractionation with the normalized $\delta^{13} \mathrm{C}$ value of $-25 \%$, were ultimately converted to a radiocarbon date.

Calibration. Radiocarbon dates were calibrated and converted into calendar ages with the OxCal v4.3 for Windows [22], by using the SHCal13 atmospheric data set [23].

\section{ACKNOWLEDGMENTS}

Authors would like to acknowledge Léon and Judy Duplessis, the owners of the Matendere Rach, Lisa-Jane Campbell of Chishakwe Ranch, Roger Whittall, the owner of the Humani Ranch and his wife Anne Whittall, Greg and Melanie Duckworth of Mokore Ranch for granting access in the ranches and for authorising the investigation and sampling of the monumental baobabs. The research was funded by the Romanian Ministry of National Education CNCS-UEFISCDI under grant PN-III-P4-ID-PCE-2016-0776, Nr. 90/2017.

\section{REFERENCES}

1. D.A. Baum, Annals of the Missouri Botanical Garden, 1995, 82, 440-471.

2. G.E. Wickens, P. Lowe, "The Baobabs: Pachycauls of Africa, Madagascar and Australia", Springer, Dordrecht, 2008, pp. 232-234, 256-257, 295-296.

3. J.D. Pettigrew, L.K. Bell, A. Bhagwandin, E. Grinan, N. Jillani, J. Meyer, E. Wabuyele, C.E. Vickers, Taxon, 2013, 61, 1240-1250. 
4. G.V. Cron, N. Karimi, K.L. Glennon, C.A. Udeh, E.T.F. Witkowski, S.M. Venter, A.E. Assobadjo, D.H. Mayne, D.A. Baum, Taxon, 2016, 65, 1037-1049.

5. D.A. Baum, R.L. Small, J.F. Wendell, Systematic Biology, 1998, 47, 181-207.

6. A. Patrut, K.F. von Reden, D.A. Lowy, A.H. Alberts, J.W. Pohlman, R. Wittmann, D. Gerlach, L. Xu, C.S. Mitchell, Tree Physiology, 2007, 27, 1569-1574.

7. A. Patrut, D.H. Mayne, K.F. von Reden, D.A. Lowy, R. Van Pelt, A.P. McNichol, M.L. Roberts, D. Margineanu, Radiocarbon, 2010, 52(2-3), 717-726.

8. A. Patrut, K.F. von Reden, R. Van Pelt, D.H. Mayne, D.A. Lowy, D. Margineanu, Annals of Forest Science, 2011, 68, 93-103.

9. A. Patrut, K.F. von Reden, P. Danthu, J-M. Leong Pock Tsy, R.T. Patrut, D.A. Lowy, PLOS One, 2015, 10(3): e0121170.

10. A. Patrut, K.F. von Reden, P. Danthu, J-M. Leong Pock-Tsy, L. Rakosy, R.T. Patrut, D.A. Lowy, D. Margineanu, Nuclear Instruments and Methods in Physics Research Section B, 2015, 361, 591-598.

11. A. Patrut, R.T. Patrut, P. Danthu, J.-M. Leong Pock-Tsy, L. Rakosy , D.A. Lowy, K.F. von Reden, PLOS One, 2016, 11(1), e0146977.

12. A. Patrut, S. Woodborne, K.F. von Reden, G. Hall, M. Hofmeyr, D.A. Lowy, R.T. Patrut, PLOS One, 2015, 10(1): e0117193.

13. A. Patrut, S. Woodborne, R.T. Patrut, L. Rakosy, D.A. Lowy, G. Hall, K.F. von Reden, Nature Plants, 2018, 4(7), 423-426.

14. A. Patrut, K.F. von Reden, D.H. Mayne, D.A. Lowy, R.T. Patrut, Nuclear Instruments and Methods in Physics Research Section B, 2013, 294, 622-626

15. A. Patrut, S. Woodborne, K.F. von Reden, G. Hall, R.T. Patrut, L. Rakosy, J-M. Leong Pock Tsy, D.A. Lowy, D. Margineanu, Radiocarbon, 2017, 59(2), 435-448.

16. P. Lindsay, R. du Toit, A. Pole, S. Romanach, "Savé Valley Conservancy: A LargeScale African Experiment in Cooperative Wildlife Management." In: H. Suich, B. Child, A. Spenceley, editors, "Evolution and Innovation in Wildlife Conservation", Earthscan, London, Sterling, VA, 2009, pp.163-186.

17. A. Patrut, L. Rakosy, R.T. Patrut, I.A. Ratiu, E. Forizs, D.A. Lowy, D. Margineanu, K.F. von Reden, Studia UBB Chemia, 2016, LXI, 4, 7-20.

18. A. Patrut, S. Woodborne, R.T. Patrut, L. Rakosy, G. Hall, I.A. Ratiu, K.F. von Reden, Studia UBB Chemia, 2017, LXII, 2, 347-354,

19. I.U. Olsson, Radiometric Methods. In: B. Berglung, editor "Handbook of Holocene palaeoecolgy and palaeohydrology", Wiley, Chichester, 1986, pp. 273-312.

20. Z. Sofer, Analytical Chemistry, 1980, 52(8), 1389-1391.

21. J.S. Vogel, J.R. Southon, D.E. Nelson, T.A. Brown, Nuclear Instruments and Methods in Physics Research Section B, 1984, 5, 289-293.

22. C. Bronk Ramsey, Radiocarbon, 2009, 51, 337-360.

23. A.G. Hogg, Q. Hua, P.G. Blackwell, M. Niu, C.E. Buck, T.P. Guilderson, T.J. Heaton, J.G. Palmer, P.J. Reimer, R.W. Reimer, C.S.M. Turney, R.H. Zimmerman, Radiocarbon, 2013, 55(4), 1889-1903. 
